\title{
Coarctação de Aorta. Do Diagnóstico Simples às Complicações Imprevisíveis
}

\author{
Munir Ebaid, Jorge Yussef Afiune
}

\author{
São Paulo, SP
}

A coarctação de aorta (CoAo) é uma das malformações cardiovasculares mais freqüentes, constituindo cerca de $5 \%$ a $8 \%$ das cardiopatias em geral, ocupando segundo as várias estatísticas, $\mathrm{o} 6^{\circ} \mathrm{ou} 7^{\circ}$ lugar entre os defeitos, predominando no sexo masculino sobre o feminino, numa proporção de 2 a 3:1. A alteração obstrutiva localiza-se na união da croça com a aorta descendente (região ístmica - entre a artéria subclávia esquerda e o ductus arteriosus ou seu remanescente), podendo envolver em maior ou menor extensão o próprio arco aórtico. A CoAo pode se apresentar como lesão isolada ou associada a outras anomalias, tais como a valva aórtica bivalvular, persistência do canal arterial, comunicação interventricular, estenose aórtica valvar ou subvalvar, sendo ainda a malformação cardiovascular mais freqüente na síndrome de Turner (20\%).

O reconhecimento clínico é relativamente simples, caracterizado pela ausência ou diminuição da amplitude dos pulsos arteriais nos membros inferiores associado a presença de pulsos amplos e hipertensão arterial nos membros superiores. É importante salientar que a presença de pressão arterial (PA) pouco alterada ou mesmo normal nos membros superiores não descarta a possibilidade desta anomalia, principalmente quando associada a presença de obstruções na via de saída do ventrículo esquerdo, grande comunicação interventricular ou ainda disfunção miocárdica. Existem outros elementos de exame físico que fazem parte do quadro, como a hiperfonese da $2^{\mathrm{a}}$ bulha nas áreas aórtica e mitral (tradução de regime de hipertensão no território sistêmico); estalido proto-sistólico aórtico, principalmente na área mitral (dilatação da aorta ascendente); sopro ocupando a meso-telessístole e avançando até a proto-mesodiástole na região do dorso esquerdo (turbulência no local da CoAo).

Assim, para o reconhecimento desta malformação é mais importante analisar estes aspectos de propedêutica física que permitem com segurança e de forma simples e econômica estabelecer o diagnóstico, independente de outros exames complementares.

Sucede que na prática diária observa-se que muitos pacientes, desde recém-nascidos até adultos, portadores de

Instituto do Coração do Hospital das Clínicas - FMUSP

Correspondência: Munir Ebaid - Incor - Av. Dr. Enéas C. Aguiar, 44 - 05403-000 São Paulo, SP

Recebido para publicação em 1/7/98

Aceito em 5/8/98
CoAo, não têm estabelecido o correto diagnóstico desta anomalia, simplesmente pela falta de um exame clínico mais acurado.

Na realidade o diagnóstico não é estabelecido não tanto pelo desconhecimento desta malformação, mas principalmente pela falta do hábito por parte da grande maioria dos médicos em aferir os pulsos e registrar a PA dos membros superiores e inferiores. Os médicos pediatras e neonatologistas, aqueles que têm a maior responsabilidade nesta observação, necessitam avaliar estes aspectos de forma rotineira e muito cuidadosa.

Muitas vezes há dificuldade em se palpar os pulsos pediosos, sobretudo nos recém-nascidos e especialmente naqueles mais "gordinhos", devendo-se nestas condições procurar palpar os pulsos femorais, além de discernir quando os pulsos nos membros superiores são mais amplos.

Muitos recém-nascidos recebem alta das maternidades sem o diagnóstico estabelecido de CoAo e, uma a duas semanas depois, retornam aos hospitais em franca insuficiência cardíaca complicada por vezes com uma broncopneumonia ou insuficiência respiratória, situação esta de alto risco para qualquer procedimento terapêutico, sobretudo a correção operatória.

Outras crianças em idade pré-escolar ou escolar, assintomáticas, têm sopro cardíaco considerado durante anos como "inocente" até que em um certo dia o pediatra resolve pedir um ecocardiograma e para surpresa de todos aquele mesmo sopro deve-se, na realidade, a uma CoAo. Esta é uma situação extremamente desagradável para o profissional e sobretudo para a família que tinha seu filho como normal e de repente transforma-se num cardiopata que necessitará de uma cirurgia cardíaca.

Outra situação que não raramente ocorre é a indicação de transplante cardíaco em crianças portadoras de disfunção miocárdica acentuada, com diagnóstico presuntivo de cardiomiopatia dilatada em franca insuficiência cardíaca. Nestas circunstâncias, por vezes surpreende-se a presença de CoAo não diagnosticada em tempo hábil.

Muitos pacientes, incluindo adolescentes e adultos, portadores de hipertensão arterial, são tratados durante anos com medicação anti-hipertensiva, porém sem um diagnóstico etiológico e diferencial estabelecido, até que seja feito um real diagnóstico de CoAo. Se isto acontecer em tempo, sem que haja uma deterioração do miocárdio, o resultado da correção operatória poderá ser ainda favorável. Al- 
guns pacientes são operados nessa idade (adultos), causando grande preocupação pelo maior risco de complicações, como insuficiência cardíaca, coronariopatia e acidente vascular cerebral.

Por vezes o diagnóstico de CoAo é realizado somente na necropsia, como por exemplo em recém-nascidos e lactentes jovens que chegam ao pronto socorro com quadro infeccioso pulmonar ou septicemia, além de insuficiência cardíaca. Alguns adultos podem ser seguidos com o diagnóstico de miocardiopatia hipertrófica durante anos até desenvolverem grave disfunção miocárdica e êxito letal, surpreendendo-se na necropsia o achado de CoAo. Poderíamos dizer que estes adultos, como se observa na prática, tiveram de 30 a 40 anos para que se fizesse o diagnóstico da cardiopatia.

Conclui-se que em todo paciente devemos obrigatoriamente palpar os pulsos dos membros inferiores e superiores, além de aferir a PA também nos quatro membros, podendo-se assim evitar todos estes transtornos secundários por falta do diagnóstico preciso desta cardiopatia, acarretando uma alta morbidade e mortalidade. Outros exames como radiografia de tórax, eletrocardiograma e ecocardiograma serão na realidade complementares e confirmatórios de um diagnóstico presuntivo já estabelecido.

A conduta terapêutica será sempre a correção desta anomalia no momento oportuno para cada caso. 